\title{
Comparação entre diagnóstico psiquiátrico e delito cometido em 100 pacientes do Manicômio Judiciário de Franco da Rocha
}

\author{
Roberto Moscatello ${ }^{1}$
}

Cesare Lombroso foi o primeiro a relacionar crime e transtorno mental (L'uomo delinqüente), através de sua teoria biológica das origens do crime. ${ }^{1}$ Posteriormente vários estudos internacionais tentaram relacionar a criminalidade sob outros aspectos, como fatores psicológicos e sociais. ${ }^{2}$ Estimativas recentes revelam que $8 \%$ a $12 \%$ da população carcerária americana sofre de um sério transtorno mental. ${ }^{3}$ Relacionar distúrbios psiquiátricos e criminalidade há muito tem sido tema de vários estudos internacionais. No Brasil esses dados são escassos .

O objetivo foi verificar os diagnósticos psiquiátricos, relacionando-os com os delitos cometidos em uma população de internos do Manicômio Judiciário de Franco da Rocha (SP). Foram entrevistados 100 internos em cumprimento de medida de segurança, todos do sexo masculino, com idades variando de 26 a 80 anos (média de 38,9 anos). Os diagnósticos foram feitos utilizando-se dos critérios do CID- $10^{4}$ e os delitos cometidos analisados segundo o Código Penal Brasileiro. ${ }^{5}$

Os resultados mostraram que entre 100 internos avaliados, $44 \%$ deles tiveram diagnóstico de esquizofrenia, dos quais quatro haviam cometido homicídios e quatorze, tentativas. O transtorno de personalidade aparece em segundo lugar com $20 \%$ dos casos, sendo que dois deles cometeram homicídios e cinco, tentativas . O Retardo Mental foi o diagnóstico vindo a seguir com $14 \%$ dos casos, dos quais dois cometeram homicídios e quatro, tentativas. Os outros diagnósticos distribuíram-se com porcentagens abaixo dos $10 \%$, sem que houvesse o predo- mínio de algum ato criminal, entre os quais furtos, assaltos, tráfico e porte de drogas, agressões, seqüestro e delitos sexuais. Entre os diagnósticos menos freqüentes observou-se paranóia, alcoolismo e epilepsia, todos relacionados com violência. Embora a maior parte da amostra tenha sido de pacientes esquizofrênicos, não foi possível relacionar a prevalência de determinado ato delinqüencial com algum transtorno psiquiátrico ou vice-versa. Entretanto, observou-se que $85 \%$ dos atos praticados revelaram violência .

\section{Referências bibliográficas}

1. Ferracutti S. Cesare Lombroso (1835 - 1907) .The Journal of Forensic Psychiatry 1996;7 (1):130-49 .

2. Ey H, Bernard P, Brisset C. Manual de Psiquiátria . $5^{\text {a }}$ ed. Rio de Janeiro (RJ): Editora Masson do Brasil Ltda; 1978 .

3. Di Cataldo F, Greer A, Profit WE. Screening prison inmates for mental disorders examination of the relationship between mental disorder and prison adjustment. Bull Am Acad Psychiatr Law 1995;23(4):573-85.

4. Organização Mundial da Saúde. Classificação de Transtornos Mentais e de Comportamento da CID-10. Porto Alegre (RS): 1993.

5. Oliveira J. Código Penal Brasileiro .11 a ed. São Paulo (SP): Editora Saraiva; 1996 .

\section{Correspondência}

Roberto Moscatello

Estrada do Governo, Km. 43, s/nº, Vila Ramos

CEP 07780-000, Franco da Rocha, SP

PABX: (011) 432-5533 Fax: (011) 432-5533 ramal 214 